\title{
Mudança de VAlores E TOLERÂNCIA ENTRE OS BRASILEIROS $^{1}$
}

\section{Ednaldo Aparecido Ribeiro ${ }^{2}$}

\begin{abstract}
Resumo
Ronald Inglehart, dentre outros pesquisadores, tem defendido que a emergência de valores pós-materialistas em nível mundial estaria sendo acompanhada de uma postura mais tolerante em relação a grupos minoritários e vítimas de preconceito. Ainda que testada satisfatoriamente no contexto das nações pós-industriais, essa hipótese não pode ser imediatamente transposta para países em desenvolvimento e materialmente não resolvidos, como os latino-americanos. 0 presente texto pretende contribuir para esse debate apresentando resultados de testes empíricos sobre essa suposta associação no contexto brasileiro. Utilizando dados produzidos pela Pesquisa Mundial de Valores, expomos um quadro sintético da evolução de alguns indicadores sobre o tema da tolerância, bem como situamos o público nacional no cenário latino-americano.
\end{abstract}

Palavras-chave: Tolerância. Valores pós-materialistas. Mudança cultural.

\footnotetext{
${ }^{1}$ Agradecemos as contribuições dos pareceristas anônimos da revista Mediações.

${ }^{2}$ Universidade Estadual de Maringá. End. eletrônico: ednaldorip@uol.com.br
} 


\section{VALUES CHANGE AND TOLERANCE AMONG BRAZILIANS \\ ABSTRACT}

Ronald Inglehart, among other researchers, has argued that the emergence of postmaterialist values in the world was being accompanied by a more tolerant attitude towards minority groups and victims of prejudice. Although satisfactorily tested in the context of post-industrial nations, this hypothesis cannot be immediately applied to developing countries and materially unresolved, such as Latin America ones. This paper aims to contribute to this debate by presenting results of empirical tests regarding this hypothesized association in the Brazilian context. Using data produced by the World Values Survey, we present a summary of the evolution of some of the indicators on the theme of tolerance as well as the place of Brazilians within the Latin American scenario.

Keywords: Tolerance. Postmaterialist values. Cultural change.

\section{INTRODUÇÃO}

0 livro The Silent Revolution, publicado por Ronald Inglehart no final da década de 1970, tem sido reconhecido como o marco inicial de um programa de pesquisas sobre valores que tem produzido grande impacto sobre as ciências sociais contemporâneas. Ao menos no campo da sociologia e da ciência política tal programa pode ser considerado um dos mais profícuos das últimas décadas, devido tanto à quantidade de trabalhos que defendem e confirmam suas principais hipóteses, quanto aos vários críticos que conquistou (RIBEIR0, 2007a).

Passadas três décadas de contínuas investigações a tese inicial da mudança lenta e gradual de um amplo espectro de valores humanos em direção a uma postura pós-materialista continua sendo testada a partir de evidências cada vez mais robustas. A teoria do desenvolvimento bumano, tal como definida por Inglehart e Welzel (2005) é o resultado atual dessa série de investigações. Ainda que mudanças conceituais relevantes possam ser identificadas ao longo desse período, a afirmação fundamental continua sendo a mesma: a despeito das significativas diferenças culturais existentes entre as nações, uma mudança nos valores estaria ocorrendo associada ao desenvolvimento econômico experimentado a partir da segunda metade do século XX, principalmente pelas sociedades industriais avançadas ou pós-industriais. Tal mudança estaria provocando alterações 
profundas no campo religioso, no mundo do trabalho, nas relações de gênero, nas normas sexuais e na atividade política (INGLEHART, 1977; 1990; 2001).

Em termos gerais, o gradual abandono de metas e objetivos relacionados à segurança física e econômica e a consequente priorização de valores relacionados a temas pós-materialistas conduziria a uma postura social mais tolerante às diferenças, como em relação ao homossexualismo, a minorias étnicas, políticas e religiosas. Uma postura mais democrática e pluralista, portanto, estaria associada à reorientação valorativa. (INGLEHART \& WELZEL, 2005)

Apesar de bem documentada e testada a partir de volumosos dados empíricos no contexto das nações economicamente desenvolvidas, acreditamos que essas afirmações e hipóteses não podem ser imediatamente transpostas para o cenário latino-americano e, sobretudo, para o brasileiro. Defendemos, portanto, a necessidade de testes rigorosos que possam corroborá-las ou refutálas em contextos como o nosso, com características bastante distintas daquelas encontradas em sociedades materialmente resolvidas. Com isso não pretendemos negar em princípio a validade universal dessas teses a partir de um apego excessivo as diversidades nacionais, mas apenas defender a necessidade de análises em cada um dos contextos específicos. 0 presente trabalho expõe os resultados de um esforço nesse sentido ao: 1) analisar os valores e prioridades valorativas do público nacional e 2) testar se essa suposta mudança subjetiva efetivamente tem sido acompanhada no nível individual por uma postura socialmente mais tolerante.

\section{Dados E METOdologia}

Para atingir esse objetivo nos valemos das bases de dados produzidas pelo projeto World Values Survey por meio de sondagens conduzidas em nosso país nos anos de 1991, 1997 e 2006. 0 WVS é uma grande investigação sobre mudanças sócio-culturais e políticas, conduzida por uma rede global de cientistas sociais a partir de surveys aplicados a amostras nacionais representativas de mais de 80 nações espalhadas por todos os continentes do planeta. Como parte de sua terceira onda de investigações, em 1991 o questionário mundial foi aplicado no Brasil a uma amostra representativa de 1782 pessoas. Na onda subsequente, de 1997, a amostra nacional foi composta por 1149 entrevistados. Finalmente, em 2006 foram entrevistados 1500 brasileiros.

Como essas bases envolvem diferentes países da América Latina, além da análise do caso brasileiro a partir dessa série histórica, também foi possível 
empreender comparações básicas com outros países da região. Não pretendemos com isso realizar uma investigação sobre o cenário latino-americano e muito menos apresentar elementos explicativos para possíveis variações nos indicadores levando em consideração as complexas peculiaridades de cada uma das nações. Com esse procedimento nosso objetivo foi tão somente captar particularidades nas dinâmicas de mudança ou permanência de valores entre a população brasileira frente aos públicos de outros países da região.

As estratégias metodológicas utilizadas envolvem estatísticas descritivas para identificar o quadro atual e as tendências dos dados no cenário nacional e latino-americano, mas também técnicas de análise bivariada para testar as hipóteses de associação mencionadas anteriormente. Para isso optamos pelo coeficiente (Gamma) de Goodman e Kruskal, útil nos casos em que as variáveis são qualitativas e medidas no nível ordinal, ou seja, com valores agrupados em categorias ordenadas (BOHRNSTEDT E KNOKE, 1982). Por se tratar de uma medida de associação simétrica ${ }^{3}$, esse coeficiente se adapta perfeitamente à nossa orientação inicial de não discutir a direção do relacionamento existente entre as variáveis. Portanto, os valores calculados para indicam tanto a capacidade de previsão da segunda variável sobre a primeira, quanto o inverso (BOHRNSTEDT E KNOKE, 1982).

Nos casos em que tais relacionamentos se mostraram significativos também utilizamos ferramentas de análise multivariada. Detalhes sobre esses procedimentos mais complexos serão apresentados nos momento sem que forem empregados.

\section{Pós-materialismo, Valores E ATITUdes DE TOLERÂNCIA EM RELAÇÃO A GRUPOS}

Utilizamos em todas as análises bivariadas e multivariadas apresentadas ao longo desse trabalho a principal ferramenta atualmente disponível para identificação da posição individual e agregada nesse complexo de mudanças valorativas descritas na teoria inglehartiana: 0 índice de materialismo/pósmaterialismo. Sendo assim, acreditamos que algumas breves informações sobre sua composição sejam necessárias.

\footnotetext{
${ }^{3}$ Simétrica porque a capacidade preditora da variável A sobre B é igual a de B sobre A, ou seja, não há alteração nos coeficientes com a inversão da ordem de predição. Nesse caso, não existe a pressuposição de dependência e independência entre as variáveis envolvidas.
} 
Nos primeiros estudos sobre o tema, tal medida era obtida através da aplicação de uma bateria composta por quatro itens que representariam os principais objetivos prioritários de qualquer sociedade:

\section{1) manter a ordem}

2) aumentar a participação dos cidadãos nas decisões importantes

3) combater o aumento de preços

4) proteger a liberdade de expressão.

Os entrevistados eram convidados a escolher sua primeira e segunda opção e, a partir de suas respostas, eram classificados como materialistas, mistos ou pósmaterialistas (INGLEHART, 1977). Apesar de continuar sendo aplicada em alguns casos específicos, nos estudos posteriores essa medida foi substituída por um índice ampliado de 12 itens. À bateria inicial foram acrescentadas mais duas, cada uma delas com quatro itens:

5) manter altas taxas de crescimento econômico

6) assegurar que o país tenha importantes forças de defesa

7) dar maior importância à opinião das pessoas sobre os assuntos em seu trabalho e comunidade

8) fazer as cidades e paisagens mais bonitas

9) manter a economia estável

10) progredir em direção a uma sociedade menos impessoal e mais bumana

\section{1) lutar contra a delinquência}

12) progredir em direção a uma sociedade onde as ideias são mais importantes que o dinheiro

Por se tratar de uma medida mais sofisticada e com maior capacidade explicativa sobre um amplo conjunto de variáveis relacionadas a diferentes temas, utilizamos ao longo da pesquisa esse índice ampliado. ${ }^{4}$

\footnotetext{
${ }^{4} 0$ referido índice tem gerado considerável polêmica e muitos pesquisadores têm se dedicado nos últimos anos a questionar a sua validade como medida efetiva das prioridades individuais (DAVIS \& DAVENPORT, 1999; SNIDERMAN, BRODY \& TETLOCK, 1991; CLARKE, et. al., 1999; CLARKE, 2000). Todavia, considerando essas criticas e submetendo a índice a diferentes testes estatísticos, pesquisa recente confirmou que o mesmo apresenta considerável consistência no cenário nacional e pode ser utilizado como uma boa medida classificatória das prioridades valorativas no nível individual (RIBEIR0, 2007b).
} 
Definida a primeira variável fundamental do estudo, podemos passar ao segundo eixo de informações que diz respeito aos valores e atitudes relativos a tolerância. Ainda que nosso objetivo não seja produzir uma reflexão conceitual acerca dos múltiplos significados do termo tolerância, algum esforço de definição deve ser realizado nesse momento.

Tomada como princípio social e político, a tolerância pode ser entendida como uma antecipação e condição para o princípio moderno da liberdade política e se liga de maneira inexorável ao modelo liberal de organização da vida social em que existe 0 " [...] reconhecimento de posições contrastantes dentro de um sistema conflituoso disciplinado por 'regras de jogo' convencionadas" (ZANONE, 1995, p. 1245). Nas discussões contemporâneas sobre as sociedades democráticas esse princípio aparece como um dos seus elementos mais relevantes. Para ficarmos em apenas um exemplo, Robert Dahl em seu já clássico Poliarquia (1997) define um regime pluralista ou poliárquico como aquele em que existe a possibilidade de contestação, que por sua vez, possui como condição primária o direito à livre expressão de ideias, valores e projetos sociais e políticos alternativos. A intolerância a crenças, valores e comportamentos diversos é uma atitude que torna inviável qualquer possibilidade de contestação e oposição, tornando impossível a existência plural e, consequentemente, a própria constituição de uma sociedade democrática.

Ao longo dessa seção apresentamos dados que possibilitam a identificação de um quadro sobre as disposições subjetivas dos brasileiros em relação a diferentes grupos sociais que ocupam posições minoritárias ou que são recorrentemente alvos privilegiados de diferentes modalidades de intolerância. Temos dois objetivos fundamentais: primeiramente queremos identificar o cenário atual e as tendências de evolução desses valores tomando o Brasil como foco central de atenção, mas também identificando possíveis peculiaridades a partir da comparação com dados de outras nações latino-americanas; nosso segundo objetivo é testar a hipótese da associação no nível individual entre pós-materialismo e posturas mais tolerantes entre os brasileiros.

Começamos por uma variável sobre a importância atribuída pelos indivíduos à tolerância como um valor. Para a obtenção da medida os entrevistados pelo WVS são apresentados a uma lista de dez qualidades, devendo selecionar as cinco que consideram mais importantes para estimular e ensinar aos seus filhos. Tolerância e respeito pelos outros é uma das opções, ao lado de independência, 
responsabilidade, criatividade, obediência, dentre outras5. Como podemos ver abaixo (TABELA 1) a maioria dos componentes da amostra nacional mencionou a tolerância e respeito aos outros como uma qualidade importante. Os percentuais das três pesquisas disponíveis indicam, entretanto, que os números atuais são menores do que os encontrados a mais de uma década atrás, ou seja, em 1991. Ainda assim, constata-se uma recuperação se compararmos esse último dado com o percentual de 1997. Mas o que chama mais atenção é o fato do Brasil ocupar a última posição entre o grupo de nações estudadas.

\section{TABELA 1. IMPORTÂNCIA DA TOLERÂNCIA E RESPEITO ENTRE PAÍSES LATINO-AMERICANOS, 1984-2008.}

\begin{tabular}{|c|c|c|}
\hline \multicolumn{2}{|l|}{ PAÍS } & \multirow{2}{*}{$\begin{array}{c}\text { Tolerância e Respeito pelos outros (\%) } \\
\text { Não é importante } \\
\end{array}$} \\
\hline \multirow{6}{*}{ Argentina } & & \\
\hline & 1984 & 56,0 \\
\hline & 1991 & 22,4 \\
\hline & 1995 & 26,9 \\
\hline & 1999 & 29,8 \\
\hline & 2006 & 29,5 \\
\hline \multirow[t]{3}{*}{ Brasil } & 1991 & 34,3 \\
\hline & 1997 & 40,6 \\
\hline & 2006 & 35,3 \\
\hline \multirow[t]{4}{*}{ Chile } & 1990 & 21,0 \\
\hline & 1996 & 38,4 \\
\hline & 2000 & 24,0 \\
\hline & 2005 & 20,9 \\
\hline \multirow[t]{3}{*}{ Peru } & 1996 & 37,0 \\
\hline & 2001 & 27,4 \\
\hline & 2008 & 33,8 \\
\hline
\end{tabular}

Fonte: European and World Values Surveys four-wave Integrated data file, 1981-2004, v.20060423, 2006 e World Values Survey, 2005-2008, vs2005a_v20081015.

Para identificar a existência e intensidade da associação entre essa medida de valorização da tolerância e a priorização de valores pós-materialistas

\footnotetext{
${ }^{5}$ Informações completas sobre todas as variáveis podem ser obtidas na página eletrônica do projeto WVS, www.worldvaluessurvey.org
} 
utilizamos o coeficiente Gamma, para o qual obtivemos nível de significância de 0,000 e $y=0,11$, indicando a ocorrência de relacionamento positivo fraco. Ou seja, tomando os dados da pesquisa de 2006 podemos afirmar que entre os brasileiros existe uma associação, ainda que fraca, entre valorizar a tolerância (e o respeito aos outros) e manifestar valores pós-materialistas.

Com o objetivo de testar a consistência desse resultado e também explorar alguns possíveis determinantes individuais da valorização dessa qualidade fundamental à vida democrática, construímos um modelo de regressão logística binária que introduz como variáveis preditoras as seguintes medidas sóciodemográficas e também atitudinais: idade, sexo, renda, escolaridade, estado civil, religião, auto-posicionamento na escala política e importância atribuída à democracia.

A regressão logística é uma ferramenta de análise estatística útil nos casos em que se pretendem predizer ou explicar a presença ou ausência de determinada característica a partir dos valores de um conjunto de medidas preditoras. Nesse sentido, é similar aos modelos de regressão linear, mas pode ser aplicado nas situações em que a variável dependente é dicotômica. As variáveis independentes ou preditoras podem ser intervalares ou categóricas, sendo que, nesse último caso, devem ser codificadas como medidas indicadoras ou dummy. Neste artigo, os coeficientes obtidos com os modelos propostos são usados como estimativas das razões de chance (estimate odds ratios) para cada uma das variáveis independentes introduzidas. (Cf. POWERS \& XIE, 2000).

Os resultados desse modelo (TABELA 2) indicam que apenas sexo e escolaridade produzem efeito estatisticamente significativo sobre a variável dependente, ou seja, apenas esses dois atributos influenciam as chances dos indivíduos estarem ou não no grupo daqueles que consideram importante a tolerância como qualidade a ser incentivada e ensinada aos filhos. A razão de chance encontrada na variável sexo aponta que ser homem reduz em $22 \%$ a probabilidade de valorização dessa qualidade, enquanto que cada elevação no nível de escolaridade produz um incremento de 6\%. Em síntese, mulheres e mais escolarizados tendem a valorizar mais essa qualidade.

${ }^{6}$ Razão de chance de $0,78-1$ x 100=-22. 


\section{TABELA 2. REGRESSÃO LOGÍSTICA COM PREDITORES DA IMPORTÂNCIA DA TOLERÂNCIA, BRASIL, 2006.}

\begin{tabular}{|l|c|c|c|c|}
\hline & B & S.E. & Razão de Chance & Sig. \\
\hline Idade &,- 01 &, 01 & 1,00 &, 251 \\
\hline Sexo &, 24 &, 12 &, 78 &, 043 \\
\hline Renda &, 03 &, 03 &, 97 &, 379 \\
\hline Escolaridade &,- 06 &, 03 & 1,06 &, 029 \\
\hline Casado &,- 20 &, 17 & 1,22 &, 250 \\
\hline Solteiro &,- 27 &, 21 & 1,33 &, 174 \\
\hline Católico &, 33 &, 18 &, 72 &, 058 \\
\hline Protestante &, 30 &, 45 &, 74 &, 500 \\
\hline Evangélico &, 31 &, 21 &, 73 &, 127 \\
\hline Espírita &, 25 &, 42 &, 78 &, 551 \\
\hline Auto-posicionamento na escala política &,- 03 &, 03 & 1,03 &, 196 \\
\hline Importância da democracia &,- 04 &, 03 & 1,04 &, 179 \\
\hline Índice de materialismo/pós-materialismo &,- 10 &, 05 & 1,11 &, 056 \\
\hline
\end{tabular}

Fonte: European and World Values Surveys four-wave Integrated data file, 1981-2004, v.20060423, 2006 e World Values Survey, 2005-2008, vs2005a_v20081015.

Os níveis de significância de todas as demais variáveis foram maiores que 0,057, inclusive 0 índice de materialismo/pós-materialismo. 0 valor reduzido do teste de associação apresentado anteriormente já indicava falta de consistência no relacionamento entre esse índice e a variável dependente, o que foi confirmado com 0 modelo logístico. Na presença de todas as demais variáveis o efeito desse preditor deixa de ser relevante.

Merece destaque o resultado para idade, pois demonstra que não existem diferenciais significativos em termos geracionais, ou seja, os mais jovens que tiveram suas experiências de socialização sob a vigência da democracia em nosso país não parecem se distinguir dos grupos etários mais velhos. Causa surpresa também o resultado para a variável sobre a importância da política, uma vez que conduz à conclusão de que a valorização de democracia como forma de governo não conduz à maior apreço pela tolerância e respeito aos outros.

Especificando um pouco mais a discussão, partimos agora para a análise de algumas variáveis relativas à tolerância e a aceitação de grupos que podem ser consideradas alvos privilegiados de discriminação e/ou intolerância. Esse tipo de

${ }^{7}$ Valor estipulado para um intervalo de confiança de $95 \%$ 
informação é extremamente difícil de ser obtida por meio de surveys, pois existe uma grande probabilidade dos indivíduos fornecerem respostas socialmente mais aceitáveis diante de perguntas diretas sobre a sua disposição subjetiva em relação a grupos marginalizados ou minoritários. 0 grande risco que o pesquisador corre nesse tipo de investigação é recolher apenas respostas que o entrevistado acredita serem menos comprometedoras e mais aceitáveis e não o que ele realmente pensa ou sente.

Como estratégia metodológica o WVS procura levantar informações sobre esse complexo tema fornecendo às pessoas uma listagem de grupos e interrogando qual deles não gostaria de ter como vizinhos. Acreditando que esse procedimento relativamente indireto pode produzir resultados menos refutáveis, nos valemos dessas informações tomando como alvo os seguintes grupos: pessoas de outras raças, pessoas com Aids, trabalhadores imigrantes ou estrangeiros, homossexuais e pessoas de outras religiões. Sempre que possível os resultados nacionais são comparados com aqueles verificados nos países latino-americanos já incluídos nas análises anteriores.

Abaixo apresentamos dados sobre a situação atual e a evolução sobre a tolerância em relação a pessoas de outras raças (TABELA 3). A situação brasileira é relativamente positiva se tomarmos os dados de 2006, pois apenas 4,4\% dos entrevistados citaram esse grupo como indesejável. A comparação com os demais países latino-americanos também revela um quadro positivo, pois apenas Argentina apresenta percentuais menores. 0 dado negativo diz respeito à elevação no percentual de brasileiros que citaram o grupo entre os anos de 1997 e 2006 . A redução desse contingente verificada entre 1991 e 1997 não se confirmou como tendência e os dados de 2006 atingiram níveis bastante próximos aos da primeira pesquisa.

0 teste de associação envolvendo essa variável e 0 índice de materialismo/ pós-materialismo não alcançou níveis mínimos de significância estatística estabelecidos, o que pode ser explicado em parte pela quase totalidade dos entrevistados (95,6\%) não ter mencionado o grupo. Ainda assim, podemos afirmar que o suposto relacionamento entre priorização de metas pós-materialistas e uma postura mais tolerante não se verifica nesse caso específico envolvendo a diversidade racial. 


\section{TABELA 3. REJEIÇÃO DE PESSOAS DE OUTRAS RAÇAS COMO VIZINHOS, PAÍSES LATINO-AMERICANOS, 1984-2008.}

\begin{tabular}{|l|l|c|}
\hline \multirow{2}{*}{ PAíS } & Pessoas de outras raças \\
\cline { 3 - 3 } Argentina & 1984 & Não citado \\
\cline { 2 - 3 } & 1991 & 97,4 \\
\cline { 2 - 3 } & 1995 & 97,3 \\
\cline { 2 - 3 } & 1999 & 95,5 \\
\cline { 2 - 3 } & 2006 & 95,3 \\
\hline Brasil & 1991 & 98,0 \\
\cline { 2 - 3 } & 1997 & 95,2 \\
\cline { 2 - 3 } & 2006 & 97,2 \\
\hline Chile & 1990 & 95,6 \\
\cline { 2 - 3 } & 1996 & 89,3 \\
\cline { 2 - 3 } & 2000 & 88,0 \\
\cline { 2 - 3 } & 2005 & 90,9 \\
\hline Peru & 1996 & 92 \\
\cline { 2 - 3 } & 2001 & 88,4 \\
\cline { 2 - 3 } & 2008 & 88,8 \\
\hline
\end{tabular}

Fonte: European and World Values Surveys four-wave Integrated data file, 1981-2004, v.20060423, 2006 e World Values Survey, 2005-2008, vs2005a_v20081015.

Em termos comparativos a situação é menos favorável quando voltamos nossa atenção para a tolerância em relação a pessoas com Aids (TABELA 4). Ainda que os dados das três pesquisas indiquem um avanço em relação aos patamares de 1991, quando 23,6\% das pessoas declararam não querer como vizinhos esse grupo de pessoas, o percentual de 14,8 para 2006 ainda revela a força do preconceito e, sobretudo, da falta de informação sobre o assunto. Além disso, é preciso apontar a existência de indícios de estabilização desse número, pois entre 1997 e 2006 a variação não alcançou nem sequer um ponto percentual, e o que é pior, para mais. Quando olhamos os dados dos outros três países constatamos que o Brasil, assim como no caso anterior, ocupa a segunda posição em termos de menor número de citações. Peruanos e chilenos são os que mais citaram o grupo, com respectivamente 24,9 e 21 pontos percentuais. A informação positiva sobre esses países e também sobre a Argentina é que se desenha mais claramente uma tendência de redução. Entre os peruanos, por exemplo, o percentual de citações que ultrapassava a casa dos 40\% sofreu sucessivas reduções e em 2006 atingiu 21 pontos. 
Passando a questão da associação, os testes indicaram a ocorrência de relacionamento estatisticamente significativo ( $p=0,000$ e $y=-0,26$ ). Como o valor do teste é negativo, podemos afirmar que na medida em que os indivíduos são dispostos em pontos mais elevados da escala de valores pós-materialistas menos provavelmente estejam entre o grupo que mencionou esse grupo de pessoas como vizinhos indesejáveis.

\section{TABELA 4. REJEIÇÃO DE PESSOAS COM AIDS COMO VIZINHOS, PAÍSES LATINO-AMERICANOS, 1984-2008}

\begin{tabular}{|l|l|c|}
\hline \multirow{2}{*}{ PAís } & Pessoas com Aids \\
\cline { 3 - 3 } Argentina & 1991 & Não citado \\
\cline { 2 - 3 } & 1995 & 68,5 \\
\cline { 2 - 3 } & 1999 & 84,4 \\
\cline { 2 - 3 } & 2006 & 88,4 \\
\hline \multirow{5}{*}{ Brasil } & 1991 & 92,9 \\
\cline { 2 - 3 } & 1997 & 76,4 \\
\cline { 2 - 3 } & 2006 & 86,0 \\
\hline \multirow{5}{*}{ Chile } & 1990 & 85,2 \\
\cline { 2 - 3 } & 1996 & 59,3 \\
\cline { 2 - 3 } & 2000 & 78,3 \\
\cline { 2 - 3 } & 2005 & 76,1 \\
\hline Peru & 1996 & 79 \\
\cline { 2 - 3 } & 2001 & 60,8 \\
\cline { 2 - 3 } & 2008 & 71,5 \\
\hline
\end{tabular}

Fonte: European and World Values Surveys four-wave Integrated data file, 1981-2004, v.20060423, 2006 e World Values Survey, 2005-2008, vs2005a_v20081015.

A partir desse dado, assim como procedemos anteriormente, construímos um modelo de regressão logística envolvendo essa variável. A Tabela 5 sintetiza os resultados desse procedimento e revela que novamente a escolaridade é um importante preditor de uma postura tolerante, sobretudo nesse caso em que a informação é um elemento fundamental contra o preconceito e o medo. Cada elevação no nível de escolaridade dos indivíduos reduz em 19\% a chance dos mesmos estarem entre aqueles que mencionaram as pessoas com Aids como vizinhos indesejáveis. 
A segunda variável que demonstrou alguma capacidade explicativa é a que mede 0 auto-posicionamento dos entrevistados na escala política que parte da "esquerda", codificada como 1 e vai até a "direita", representada pelo valor 10. Ainda que nem todas as pessoas saibam definir claramente essas posições relativas do espectro ideológico, é interessante notar que cada ponto adicional na escala produz um aumento de $8 \%$ na chance do indivíduo fazer parte do grupo que não deseja ter como vizinhos portadores dessa doença.

Por fim, confirmando a consistência dos resultados da análise bivariada previamente apresentada, o índice de materialismo/pós-materialismo também aparece como preditor relevante. Cada elevação nessa escala de valores reduz em $26 \%$ a chance de o indivíduo estar entre aqueles que citaram o grupo de que estamos tratando.

TABELA 5. REGRESSÃO LOGÍSTICA COM PREDITORES DA REJEIÇÃO DE PESSOAS COM AIDS COMO VIZINHOS, BRASIL, 2006.

\begin{tabular}{|l|c|c|c|c|}
\hline & B & S.E. & Razão de Chance & Sig. \\
\hline Idade &,- 01 &, 01 & 1,00 &, 467 \\
\hline Sexo &, 05 &, 17 & 1,05 &, 780 \\
\hline Renda &,- 01 &, 04 &, 98 &, 946 \\
\hline Escolaridade &,- 21 &, 05 &, 81 &, 000 \\
\hline Casado &, 04 &, 24 & 1,04 &, 863 \\
\hline Solteiro &, 19 &, 30 & 1,21 &, 521 \\
\hline Católico &,- 27 &, 22 &, 76 &, 224 \\
\hline Protestante &,- 15 &, 60 &, 86 &, 802 \\
\hline Evangélico &,- 70 &, 28 &, 49 &, 127 \\
\hline Espírita & $-1,73$ & 1,05 &, 18 &, 100 \\
\hline Auto-posicionamento na escala política &, 07 &, 03 & 1,08 &, 029 \\
\hline Importância da democracia &, 06 &, 04 & 1,06 &, 137 \\
\hline Índice de materialismo/pós-materialismo &,- 30 &, 08 &, 74 &, 000 \\
\hline
\end{tabular}

Fonte: World Values Survey, 2005-2008, vs2005a_v20081015.

0 grupo seguinte é composto por trabalhadores imigrantes ou estrangeiros, para os quais encontramos níveis de rejeição relativamente reduzidos no cenário nacional, com 6,7\% de citações em 2006 (TABELA 6). 0 dado negativo diz respeito à elevação que aparece na comparação com os dados de 1997, quando apenas 
3,6\% dos entrevistados mencionaram esse grupo como vizinhos indesejáveis. Com exceção dessa tendência de elevação, exclusividade do caso brasileiro, os dados dos demais países revelam uma situação regional semelhante, com Argentina apresentando o menor percentual (3 pontos) e Chile o maior (9,3).

Em relação a esse grupo também constatamos a existência de associação estatisticamente significativa $(p=0,039)$, negativa e de fraca intensidade $(y=-$ 0,16). Com esse valor bastante reduzido no coeficiente de associação e também em razão da baixa frequência de citações, a análise multivariada não retornou efeitos significativos para nenhum dos preditores utilizados nos casos anteriores. Ou seja, não existem diferenciais em termos de sexo, renda, escolaridade, dentre outros, porque a quase totalidade (mais de 93\%) dos entrevistados brasileiros não mencionou os trabalhadores imigrantes ou estrangeiros como vizinhos não desejáveis.

\section{TABELA 6. REJEIÇÃO DE TRABALHADORES IMIGRANTES OU ESTRANGEIROS COMO VIZINHOS, PAÍSES LATINO-AMERICANOS, 1984-2008}

\begin{tabular}{|l|c|c|}
\hline \multirow{2}{*}{ PAÍS } & \multicolumn{2}{|c|}{ Trabalhadores imigrantes ou estrangeiros } \\
\cline { 3 - 3 } Argentina & 1984 & Não citado \\
\cline { 2 - 3 } & 1991 & 99,4 \\
\cline { 2 - 3 } & 1995 & 97,9 \\
\cline { 2 - 3 } & 1999 & 94,6 \\
\cline { 2 - 3 } & 2006 & 94,1 \\
\hline Brasil & 1991 & 97 \\
\cline { 2 - 3 } & 1997 & 96,1 \\
\cline { 2 - 3 } & 2006 & 96,4 \\
\hline Chile & 1990 & 93,3 \\
\cline { 2 - 3 } & 1996 & 88,1 \\
\cline { 2 - 3 } & 2000 & 88,3 \\
\cline { 2 - 3 } & 2005 & 89,2 \\
\hline \multirow{5}{*}{ Peru } & 1996 & 90,7 \\
\cline { 2 - 3 } & 2001 & 89,8 \\
\cline { 2 - 3 } & 2008 & 89,1 \\
\hline
\end{tabular}

Fonte: European and World Values Surveys four-wave Integrated data file, 1981-2004, v.20060423, 2006 e World Values Survey, 2005-2008, vs2005a_v20081015. 
A próxima variável toma como alvo os homossexuais e desta forma toca em uma das dimensões mais abordadas pelos defensores da teoria do desenvolvimento humano. Como já mencionamos anteriormente, a adesão aos valores pósmaterialistas estaria associada a uma postura mais tolerante com as orientações sexuais que não se enquadram no padrão heterossexual dominante (INGLEHART \& WELZEL, 2005).

Apesar de 21,5\% dos entrevistados da última amostra brasileira ainda citarem os homossexuais como vizinhos indesejáveis, a comparação com os resultados das duas pesquisas anteriores apontam para uma tendência de redução, com variação de quase 10 pontos nesses 15 anos (TABELA 7). Novamente a Argentina aparece como o país em que ocorre o menor número de citações, com 14,5\%. 0 Brasil apresenta o segundo menor, seguido por Chile (33,3\%) e Peru (41,8\%). A tendência de queda dessa postura preconceituosa se verifica em todos os países, em alguns casos de maneira significativa, como no Chile.

\section{TABELA 7. REJEIÇÃO DE HOMOSSEXUAIS COMO VIZINHOS, PAÍSES LATINO-AMERICANOS, 1984-2008}

\begin{tabular}{|l|c|c|}
\hline \multirow{2}{*}{ PAÍS } & Homossexuais \\
\cline { 2 - 3 } Argentina & 1991 & Não citado \\
\cline { 2 - 3 } & 1995 & 61,1 \\
\cline { 2 - 3 } & 1999 & 71,3 \\
\cline { 2 - 3 } & 2006 & 78,1 \\
\hline \multirow{4}{*}{ Brasil } & 1991 & 85,5 \\
\cline { 2 - 3 } & 1997 & 69,8 \\
\cline { 2 - 3 } & 2006 & 73,7 \\
\hline Chile & 1990 & 78,5 \\
\cline { 2 - 3 } & 1996 & 42,5 \\
\cline { 2 - 3 } & 2000 & 57,6 \\
\cline { 2 - 3 } & 2005 & 66,5 \\
\hline Peru & 1996 & 66,7 \\
\cline { 2 - 3 } & 2001 & 46,2 \\
\cline { 2 - 3 } & 2008 & 50,8 \\
\hline
\end{tabular}

Fonte: European and World Values Surveys four-wave Integrated data file, 1981-2004, v.20060423, 2006 e World Values Survey, 2005-2008, vs2005a_v20081015. 
Passando à questão dasuposta associação com o fenômeno pós-materialista, a análise bivariada é favorável à hipótese. 0 nível de significância $(\phi=0,000)$ e 0 valor do teste $(y=-0,21)$ revelam que o relacionamento é significativo, negativo e de fraca intensidade. 0 modelo multivariado binário (TABELA 8) confirmou esse resultado apontando que a elevação em um ponto na escala de pós-materialismo produz redução de 19\% na chance do indivíduo mencionar o referido grupo como pessoas que não gostaria de ter como vizinhos. Mais uma vez a educação aparece como bom preditor, sendo que cada nível de escolaridade adicionado reduz em 14\% a chance de mencionar o grupo. Nesse modelo também uma variável sobre a denominação religiosa dos entrevistados demonstrou possuir capacidade explicativa. Ser espírita reduz em $88 \%$ a chance de fazer parte do grupo que rejeita os homossexuais como vizinhos.

\section{TABELA 8. REGRESSÃO LOGÍSTICA COM PREDITORES DA REJEIÇÃO DE HOMOSSEXUAIS COMO VIZINHOS, BRASIL, 2006.}

\begin{tabular}{lcccc}
\hline & B & S.E. & Razão de Chance & Sig. \\
\hline Idade &, 01 &, 01 & 1,01 &, 116 \\
\hline Sexo &, 23 &, 14 & 1,26 &, 094 \\
\hline Renda &, 02 &, 03 & 1,02 &, 551 \\
\hline Escolaridade &,- 15 &, 03 &, 86 &, 000 \\
\hline Casado &, 23 &, 20 & 1,26 &, 255 \\
\hline Solteiro &,- 03 &, 26 &, 97 &, 900 \\
\hline Católico &,- 13 &, 20 &, 88 &, 512 \\
\hline Protestante &,- 07 &, 54 &, 93 &, 901 \\
\hline Evangélico &, 02 &, 23 & 1,02 &, 943 \\
\hline Espírita & $-2,12$ & 1,04 &, 12 &, 041 \\
\hline Auto-posicionamento na escala política &, 03 &, 03 & 1,03 &, 248 \\
\hline Importância da democracia &,- 03 &, 03 &, 97 &, 312 \\
\hline Índice de materialismo/pós-materialismo &,- 21 &, 06 &, 81 &, 001 \\
\hline
\end{tabular}

Fonte: World Values Survey, 2005-2008, vs2005a_v20081015.

A última variável diz respeito às disposições dos entrevistados em relação a pessoas de outras religiões. Infelizmente nesse caso não dispomos de informações da pesquisa de 1991 realizada em nosso país. Tomando o percentual da última sondagem verificamos bons indícios de tolerância religiosa, uma vez que apenas 6\% dos entrevistados apontaram esse grupo como vizinhos indesejáveis (TABELA 
9). Outro dado positivo é a redução de 50\% no percentual de citações, caindo de 13,2 para 6 pontos. Na comparação, entretanto, ainda apresentamos contingente maior do que os registrados na Argentina (1,4\%) e no Chile (5,3\%).

0 teste de associação com o índice de materialismo/pós-materialismo não apontou relacionamento significativo, o que novamente pode ser explicado pela baixa variação da medida, uma vez que a quase totalidade dos participantes da pesquisa se mostraram tolerantes em termos religiosos.

\section{TABELA 9. REJEIÇÃO DE PESSOAS DE OUTRAS RELIGIÕES COMO VIZINHOS, PAÍSES LATINO-AMERICANOS, 1997-2008}

\begin{tabular}{|l|c|c|}
\hline \multirow{2}{*}{ PAís } & Pessoas de outras religiões \\
\cline { 3 - 3 } & & Não citado \\
\hline Argentina & 2006 & 98,6 \\
\hline Brasil & 1997 & 86,8 \\
\cline { 2 - 3 } & 2006 & 94,0 \\
\hline Chile & 2005 & 94,7 \\
\hline Peru & 2008 & 92,5 \\
\hline
\end{tabular}

Fonte: European and World Values Surveys four-wave Integrated data file, 1981-2004, v.20060423, 2006 e World Values Survey, 2005-2008, vs2005a_v20081015.

Para finalizar, realizamos testes para descobrir se existia alguma uniformidade na variação dessas cinco medidas. Nossa intenção era saber se a citação de um dos grupos era acompanhada também pela menção aos demais, indicando uma postura intolerante (ou tolerante, no sentido inverso) generalizada. A primeira ferramenta utilizada foi o teste de consistência interna Alpha de Cronbach, para o qual encontramos 0,69 como valor. Como números positivos iguais ou maiores a 0,70 são considerados como patamares seguros aceitamos 0 observado como indicador de consistência (Morgan, et al, 2004).

Adicionalmente também submetemos as variáveis a uma técnica multivariada de redução de dimensionalidade chamada de análise fatorial (HAIR, et al., 1987). Esse procedimento indicou que $48,73 \%$ da variação conjunta das cinco medidas podem ser explicados por apenas um fator ou variável latente, o que justifica procedimentos de redução, tais como a produção de um índice somatório que represente a posição de cada entrevistado em razão de suas respostas em relação aos cinco grupos estudados. Como cada uma das variáveis é binária, possuindo valores 0 (para não citação) e 1 (para citação), o índice composto possuí uma 
escala que vai de 0 (representando a situação em que o entrevistado não menciona nenhum dos grupos como vizinhos indesejáveis) e 5 (para a situação em que 0 indivíduo cita todos os cinco grupos). Como o avançar na escala representa maior intolerância, chamamos essa medida integrada de Índice de Intolerância.

Com esse índice realizamos um novo teste de associação para identificar se existiria relacionamento significativo entre o mesmo e a medida de materialismo/ pós-materialismo. Confirmando a hipótese dos defensores da teoria do desenvolvimento humano encontramos relacionamento significativo $(p=0,000)$, e no sentido negativo $(y=-0,21)$, como poderíamos prever a partir dos argumentos teóricos apresentados na introdução. Tal resultado indica que a adesão aos valores pós-materialistas está associada negativamente a uma postura intolerante, ao menos em relação aos grupos envolvidos em nossa análise.

Para testar a consistência desse achado e também investigar efeitos de outros preditores, também construímos um modelo de regressão múltipla tendo como variável dependente esse índice somatório que criamos. Ainda que o modelo não seja robusto em termos de capacidade explicativa, apresentando um $\mathrm{R}^{2}$ ajustado de apenas 0,02 , as informações sobre os efeitos das variáveis independentes são interessantes (TABELA 10). A primeira delas diz respeito à permanência de apenas duas variáveis no modelo, escolaridade e a medida de pós-materialismo, após a exclusão de todas aquelas que não alcançaram os níveis estabelecidos de significância estatística $(0,05)$. Ambas produzem efeito negativo, como poderíamos esperar, e com intensidades relativamente próximas, com vantagem para a primeira. Os resultados desse último procedimento, portanto, confirmam todas as análises particularizadas que apresentamos ao longo dessa seção e contribuem para sustentar a afirmação de que maior escolarização e manifestação de prioridades pós-materialistas conduzem a maior tolerância racial, religiosa, dentre outras abordadas.

\section{TABELA 10. REGRESSÃO COM PREDITORES DA INTOLERÃNCIA, BRASIL, 2006.}

\begin{tabular}{|l|c|c|}
\hline & $\mathrm{B}$ & Beta \\
\hline Escolaridade &,- 05 &,- 11 \\
\hline Índice de Materialismo/Pós-materialismo &,- 08 &,- 09 \\
\hline $\mathrm{R}^{2}$ ajustado & 0,023 & \\
\hline
\end{tabular}

Fonte: World Values Survey, 2005-2008, vs2005a_v20081015. 


\section{CONSIDERAÇõES FINAIS}

Os dados apresentados ao longo desse trabalho favorecem algumas conclusões acerca da suposta relação entre a chamada síndrome de valores pós-materialistas e a ocorrência de uma salutar postura tolerante, pluralista e democrática no contexto brasileiro. A variedade de temas e grupos envolvidos nos testes, entretanto, exige algum esforço de síntese para definir um quadro geral. Tomando inicialmente a dimensão da aceitação de grupos minoritários ou vítimas frequentes de discriminação ou preconceito, podemos identificar uma situação positiva se tomarmos a situação nacional isoladamente, pois constatamos que a maioria valoriza a tolerância e o respeito aos outros e apenas reduzidas minorias citaram os grupos mencionados acima como vizinhos indesejáveis. Todavia, merece destaque a situação dos portadores de Aids, pois apesar do percentual de citações $(14,8 \%)$ ser estatisticamente reduzido não pode ser tomado como motivo para comemoraç̃̃es. Nesse caso inclusive constatamos uma tendência de estabilização dos percentuais, o que deve preocupar.

No quadro latino americano o Brasil ocupa uma posição confortável, ficando na maioria dos casos atrás apenas da Argentina em termos de maior tolerância. É importante esclarecer que não tivemos pretensões comparativas nesse trabalho, ao menos não em stricto sensu, pois isso exigiria um esforço explicativo dos dados apresentados à luz das marcantes diferenças culturais existentes em cada um dos países selecionados para facilitar a identificação da posição do Brasil no quadro regional. Para mencionar apenas um dos problemas que deveriam ser abordados em uma análise comparada rigorosa, seria necessário apresentar elementos que pudessem esclarecer o fato de que em alguns indicadores de tolerância Chile e Peru se aproximem significativamente, a despeito de apresentarem importantes diferenças em termos educacionais. Essas e várias outras questões que eventualmente possam ser suscitadas pela exposição e análise dos dados que oferecemos são da mais alta relevância, mas o seu esclarecimento demanda a realização de análises adicionais que escapam os limites que propomos para 0 texto.

Tratando especificamente da associação, apesar da análise bivariada em alguns momentos indicar a inexistência de relacionamento ou coeficientes muito baixos, a análise multivariada de cada item e também do índice somatório são favoráveis à teoria do desenvolvimento humano. Em outros termos, é entre os indivíduos que manifestam maior adesão aos valores pós-materialista que 
encontramos maior propensão à tolerância em relação aos grupos analisados. Mas gostaríamos de chamar a atenção para algo que, se não é novo, merece ser reforçado: a relevância da variável educação. Em diferentes momentos verificamos que o nível de escolaridade dos entrevistados é um preditor importante de seus valores e disposições, sempre com efeito superior ao produzido pelo índice de materialismo/pós-materialismo. Não queremos com isso minimizar a relevância dessa última medida, mas apenas apontar que mais do que valorizar essa ou aquela meta societal ou objetivo individual, o nível de educação e informação dos cidadãos influencia direta e positivamente suas posturas tolerantes.

\section{REFERÊNCIAS}

BOHRNSTEDT, George G. \& KNOKE, David. Statistics for Social Data Analysis. New York: Peacock, 1982.

CLARKE, Harold. D. et al. The effect of economic priorities on the measurement of values change: new experimental evidence. American Political Science Review, n. $93,1999$.

CLARKE, Harold. D. Refutations affirmed: conversations concerning the EuroBarometer Values Battery. Political Research Quarterly, v. 53, n.3, 2000.

DAHL, Robert. Poliarquia. São Paulo, Edusp, 1997.

DAVIS, Darren W.; DAVENPORT, Christian. Assessing the validity of the Postmaterialism Index. American Political Science Review, v. 93, n.3, 1999.

HAIR, Joseph F. et al. Multivariate data analysis. New York: Macmillan, 1987.

INGLEHART, Ronald. The Silent Revolution. Princeton: Princeton University Press, 1977.

. Culture shift in advanced industrial society. Princeton: Princeton University Press, 1990.

. Modernización y posmodernización: el cambio cultural, económico

y político en 43 sociedades. Madrid: Centro de Investigaciones Sociológicas/Siglo Veintiuno, 2001.

INGLEHART, Ronald; WELZEL, Christian. Modernization, cultural change, and democracy: the human development sequence. New York: Cambridge University Press, 2005. 
MORGAN, George A. et al. SPSS for introductory statistics. New Jersey: Lawrence Erlbaum Associates Publishers, 2004.

POWERS, Daniel A.; XIE, Yu. Statistical methods for categorical data analysis. New York: Academic Press, 2000.

RIBEIR0, Ednaldo A. Teoria do desenvolvimento humano, cultura política e democracia. Revista Brasileira de Informação Bibliográfica em Ciências Sociais, BIB, São Paulo, n. 64, 2007a.

A consistência das medidas de pós-materialismo: testando a validade dos índices propostos por R. Inglehart no contexto brasileiro. Sociedade e Estado, Brasília, v.22, n.2, 2007b.

SNIDERMAN, Paul M.; BRODY, Richard A.; TETLOCK, Philip E. Reasoning and Choice: explorations in political psychology. Cambridge: Cambridge University Press, 1991.

ZANONE, Vaderio. Tolerância. In: BOBBI0, Norberto. et al. Dicionário de Política. Brasília: Ed. UNB, 1995. 